\title{
Reliability modeling of high-voltage power lines in a sharply continental climate
}

\author{
Shamil Rashidovich Khasanov ${ }^{1, *}$, Elena Ivanovna Gracheva ${ }^{1}$, Muhayo Islomovna Toshkhodzhaeva ${ }^{2}$, Shakhboz \\ Tolibjonovich Dadabaev ${ }^{2}$, and Dilafruz Saidulloevna Mirkhalikova ${ }^{2}$ \\ ${ }^{1}$ Department Power supply of industrial enterprises, Kazan State Power Engineering University, Kazan, Russia \\ ${ }^{2}$ Department of Power Supply and Automation, Khujand Polytechnic Institute of the Tajik Technical University Named after \\ Academician M.S. Osimi, Khujand 735700, Tajikistan
}

\begin{abstract}
One of the important elements of the high-voltage transmission line is $110 \mathrm{kV}$, the damage of which leads to under-supply of electricity, i.e. reducing the reliability of the lines. Damage to the reinforcement from the applied load occurs due to material fatigue. The main causes of damage to the reinforcement are ambient temperatures and wind forces on this element. Periodic kinks of the wire are observed at the places of installation of the connecting and supporting clamps, vibration dampers, and cyclic lateral forces arise. The simultaneous impact of the above efforts leads to fatigue damage to the suspension systems. From the cyclic load, the nodes of rigid structures are destroyed, which bear the maximum load.
\end{abstract}

\section{Introduction}

Reliable and uninterrupted power supply to consumers mainly depends on the normal functioning of electric networks. The reliable operation of high-voltage power lines depends on not only operating conditions, technological conditions, operating modes of electric power networks, but also on the climatic conditions of the region. Abnormal cooling in the winter season, a sharp increase in temperature in the summer, increased wind, intense solar radiation, the presence of dust in the form of suspended particles; undoubtedly affect the operation of high-voltage power lines. As studies of high-voltage power lines $110 \mathrm{kV}$ failures show, the main reason for the decrease in the reliability of high-voltage power lines $110,220 \mathrm{kV}$ is the influence of external factors, such as rain, snow, wind [1, 2 and 3]. The electric network refers to large systems that are characterized by a multiplicity of elements and the connections between them. To study large electric power systems, a systematic approach is used. The object of study is considered as a set of elements; therefore, their relationship is defined as an integral property of this set [4].

\section{Methodology}

Sag arrows and voltage across the wire vary with current load and ambient temperature. With increasing ambient temperature, the sag increases, therefore, the voltage on the wire decreases. With decreasing temperature, the opposite phenomenon occurs. When using the wires in the calculations, the values of the following temperatures are taken into account $[5,6]$ :
1. The highest temperature at which the wires extends the most and the sag reach the highest values.

2. The lowest temperature value at which the wires are reduced to the greatest degree and the voltage in them reaches the highest values.

3. The average annual temperature that meets the operating conditions.

To analyze the impact of natural and climatic loads on the $110 \mathrm{kV}$ high voltage transmission line, it is necessary to determine the initial parameters of the line, which reflect the state of the high voltage cable under normal operating conditions. For conditions of sharply continental climate, the state of high-voltage transmission lines is accepted in the absence of wind and the temperature of the conductor material $+25^{\circ} \mathrm{C}$.

When determining the initial mechanical loads, the total tension $T t$ is calculated, which consists of the vertical component $V t$ and the horizontal component $\mathrm{Ht}$. There is a need to calculate the sag for all selected variation $f t$ wire according to the formula 1 . The mechanical stress in the conductors $\sigma_{t}$ is determined from the equation of state $[7,8]$ :

$$
f_{t}=\frac{\gamma_{1} \cdot\left(l_{c a l}\right)^{2}}{8 \cdot \sigma_{t}}
$$

$$
\begin{aligned}
& \sigma_{t}-\frac{\gamma_{1}^{2} \cdot\left(l_{c a l}\right)^{2} \cdot E}{24\left(\sigma_{t}\right)^{2}}=\sigma_{d o p}- \\
& -\frac{\gamma_{1}^{2} \cdot\left(l_{c a l}\right)^{2} \cdot E}{24\left(\sigma_{d o p}\right)^{2}}-\alpha_{l . r} \cdot E \cdot\left(t-t_{n}\right)
\end{aligned}
$$

\footnotetext{
* Corresponding author: shukrona14012011@mail.ru
} 
where $t$ is the ambient temperature, ${ }^{\circ} \mathrm{C} ; t=-20{ }^{\circ} \mathrm{C}$ minimum temperature.

Components horizontal full tension of the conductor, $H_{t}[7,9$ and 10]:

$$
H_{t}=\frac{M_{0} \cdot 10^{-3} \cdot\left(l_{c a l}\right)^{2}}{8 \cdot f_{t}}
$$

Components vertical full tension of the conductor, $V_{t}$ :

$$
V_{t}=M_{\mathrm{O}} \cdot 10^{-3} \cdot l_{c a l}
$$

Full wire tension, $T_{t}$ :

$$
T_{t}=\sqrt{\left(H_{t}\right)^{2}+\left(V_{t}\right)^{2}}
$$

\section{Modeling and simulation result}

To calculate and build the dependencies of the sag arrows and tensions on the climatic loads, a software module was compiled in the Matlab / Simulink program [11-14]. The tension $H v, V v, T v$ that occur in the wires and changes in the sag arrows, and the voltage on the wire when the ambient temperature changes $t=0,10$, $20,25,30,40,45^{\circ} \mathrm{C}$ at a constant wind speed $\vartheta=10 \mathrm{~m} / \mathrm{s}$ are shown in figures 1 and 2 [7, 15 and 16].

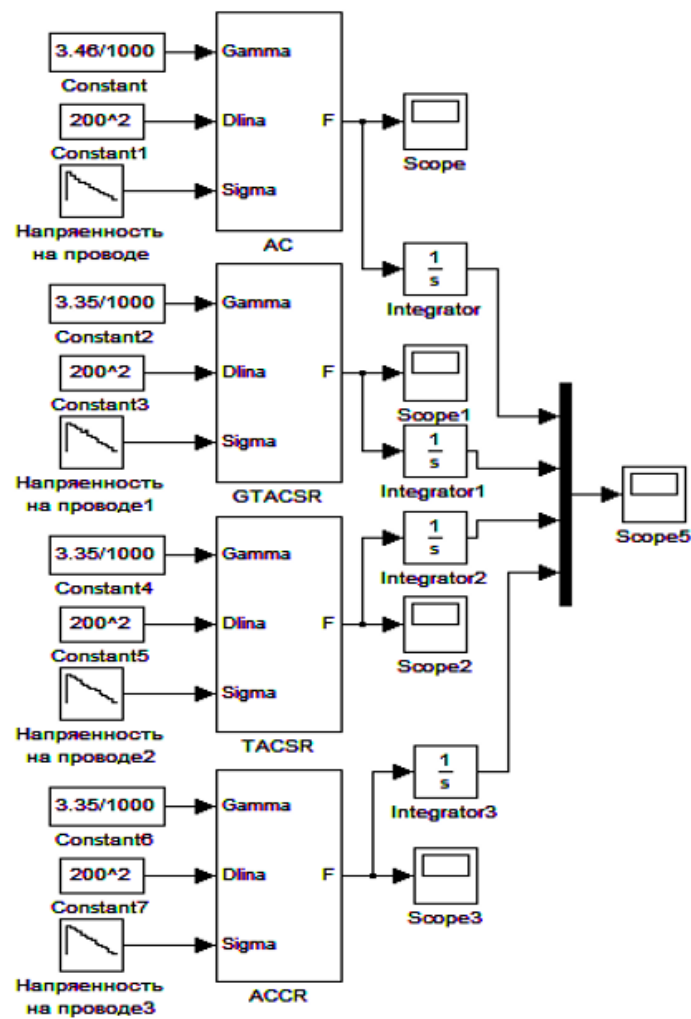

Fig. 1. Computer model for determining the sag of wires depending on temperature changes.

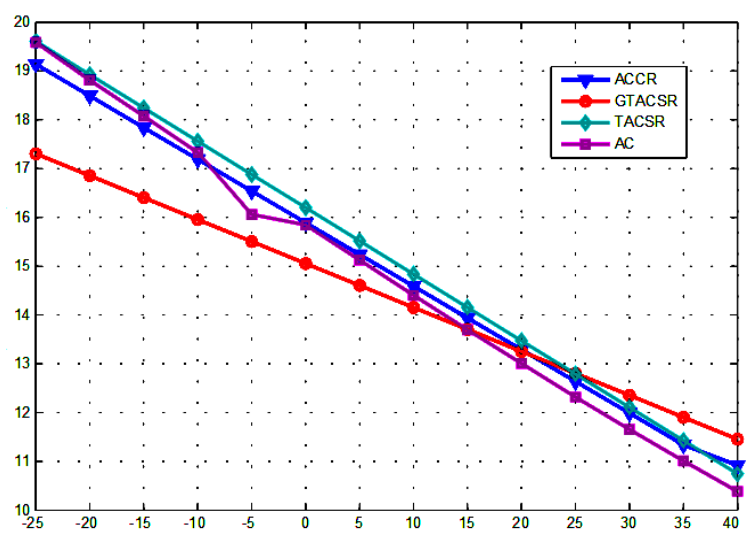

Fig. 2. The voltage on the wire depending from ambient temperature.

As can be seen from Figure 2, the voltage of all wires decreases linearly with increasing temperature. In the temperature range $-25 \ldots+40{ }^{\circ} \mathrm{C}$, the average decrease is 1.58 times. A characteristic of all wires is a temperature of $+15{ }^{\circ} \mathrm{C}$, at which the curves cross the permissible voltage. The tension on the GTACSR wire at a temperature of $-25{ }^{\circ} \mathrm{C}$ is $10 \%$ less than that of the $\mathrm{AC}$ wire, and at a maximum temperature of $40{ }^{\circ} \mathrm{C} 10.3 \%$ more than that of the $\mathrm{AC}$ wire. A distinctive feature of GTACSR wires is a lower coefficient of temperature dependence, which is due to the presence of a gap between the conductors and the composite core [17-19].

The tension on the TACSR, ACCR, AC wires at the minimum temperature has the same value, but at maximum temperatures it is $10.3 \%$ higher than on the $\mathrm{AC}$ wires. This is due to the fact that the conductors are made of heat-resistant aluminum of the TAL type with the addition of zirconium, which makes it possible to increase the mechanical strength of the wire. TACSR and ACCR wires are 1.4 times stronger than permissible at minimum temperatures, and at maximum temperatures 1.3 times less than acceptable values. A distinctive feature of high-temperature wires is that at maximum temperatures they have more tension than traditional wires, therefore, the sag will be less than that of an AC wire. The change in the sag of the wires depending on the change in ambient temperature is shown in Figure 3

As can be seen from Figure 3, at the maximum temperature for all types of wires compared with the AC, the sag is greater, at maximum temperatures less than the wires of the AC. It should be noted that at maximum temperatures the sag of all wire grades is significantly less than the critical value. The dependence of the tension of the wires depending on the ambient temperature is shown in figure 4. 


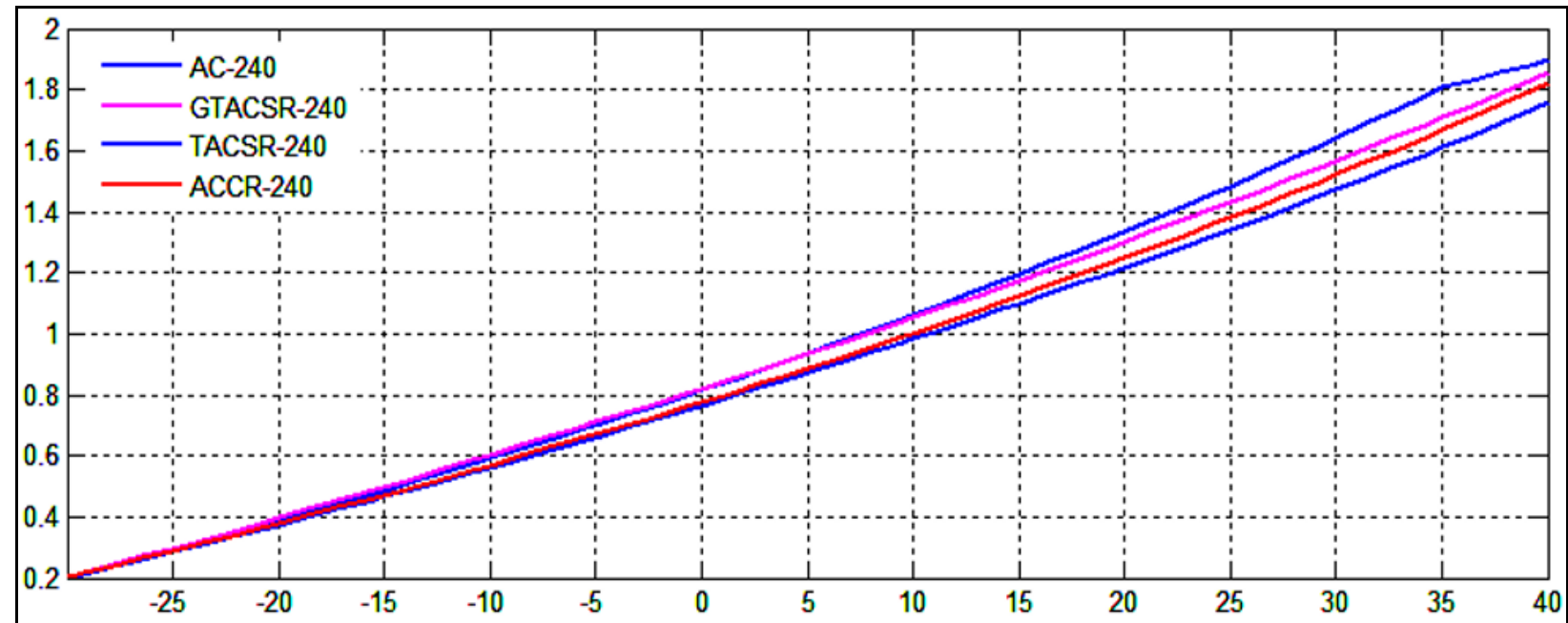

Fig. 3. Changing of wire sag depending on the ambient temperature.

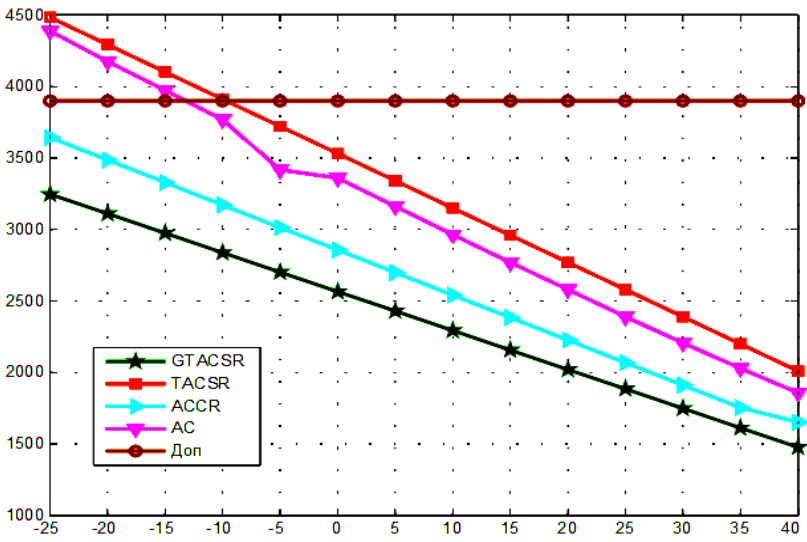

Fig. 4. Dependence of wire tension on ambient temperature.

As can be seen from Figure 4, the dependence of the full tension on the temperature on the wires is mainly due to the mechanical properties of the conductive materials. In the temperature range $-25 \ldots .+10^{\circ} \mathrm{C}$, for TACSR and $\mathrm{AC}$ wires, the tension exceeds the permissible value, and for GTACSR and ACCR wires in the entire temperature range the tension is less than the allowable value.

The tension $H_{v}, V_{v}, T_{v}$ that occur in the conductors without ice, with a changing wind speed $v=0,10,20,30$ $\mathrm{m} / \mathrm{s}$, at a certain ambient temperature $t_{g}=+10{ }^{\circ} \mathrm{C}$, are calculated according to the equation 12 . The value of the coefficient of non-uniformity depending on the magnitude of the wind speed $\alpha$, the standard high-speed wind pressure at a height of $10 \mathrm{~m}$ from the earth's surface, taking into account the qn downwind region and the coefficient of increase of the high-speed wind pressure in height, are adopted according to $[6,7]$. The region under consideration corresponds to the III district downwind, the repeat period is 10 years.

Sag arrows $f_{\vartheta}$ are determined from the expression

$$
f_{\vartheta}=\frac{\gamma_{4} \cdot\left(l_{c a l}\right)}{8 \cdot \sigma_{\vartheta}}
$$

The specific load on the wire $\gamma_{4}$ is calculated by the formula:

$$
\gamma_{4}=\sqrt{\gamma_{1}^{2}}+\left(\frac{\alpha \cdot C_{x} \cdot \vartheta^{2} \cdot d_{n}}{1.6 \cdot 10^{-3} \cdot F}\right)^{2}
$$

The voltage in the wire is calculated by the formula:

$$
\begin{aligned}
& \sigma_{v}-\frac{\gamma_{6}^{2} \times\left(l_{c a l}\right)^{2} \times E}{24 \times\left(\sigma_{v}\right)^{2}}=\sigma_{d o p}- \\
& -\frac{\gamma_{1}^{2} \times\left(l_{c a l}\right)^{2} \times E}{24 \times\left(\sigma_{d o p}\right)^{2}}-\alpha_{l . r .} \times E \times\left(t_{g}-t_{n}\right)
\end{aligned}
$$

The horizontal components $H_{v}$ of the full tension of the wire are found from the expression:

$$
\begin{gathered}
H_{v}=\frac{\sqrt{\left(M_{0} \cdot 10^{-3}\right)^{2}+\left(P_{v}\right)^{2}} \cdot\left(l_{c a l}\right)^{2}}{8 \cdot f_{v}} \\
P_{v}=6,25 \cdot 10^{-5} \cdot \alpha \cdot C_{x} \cdot v^{2} \cdot d_{n} .
\end{gathered}
$$

The vertical components $V_{v}$ of the full tensile wire are calculated by the formula (3.21):

$$
\mathrm{V}_{v}=\sqrt{\left(M_{0} \cdot 10^{-3} \cdot l_{c a l}\right)^{2}+\left(P_{v} \cdot l_{c a l}\right)^{2}}
$$

Full conductor tension, $T_{v}$ :

$$
T_{v}=\sqrt{\left(H_{v}\right)^{2}+\left(V_{v}\right)^{2}}
$$

Graphs of changes in tension and sag arrows when changing wind speed at a certain air temperature $t_{g}=10$ ${ }^{\circ} \mathrm{C}$ are presented in figure 5 . 


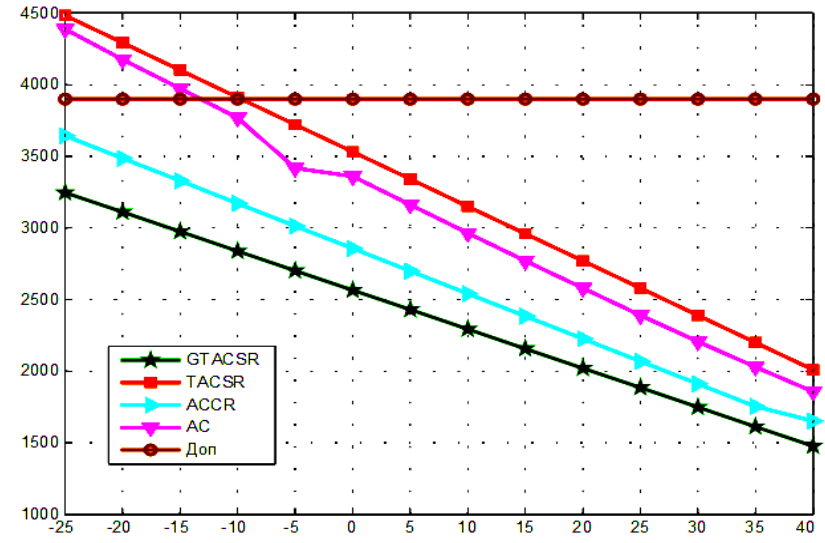

Fig. 5. Change of a arrow of a sag of wires depending from changes in wind speed.

The values of the changes in the sag depending on the wind speed are the same for GTACSR, TACSR and $\mathrm{AC}$ wires, but for the ACCR wire at the maximum wind speed, the change in the sag is $11 \%$ less than for $\mathrm{AC}$ wires. At the maximum value of wind speed, the value of the change in the arrow of the sag is less than permissible. This is due to the fact that in sharply continental climates there is practically no ice formation on the wires. The dependence of the tension of the wires depending on the wind speed is presented in Figure 6.

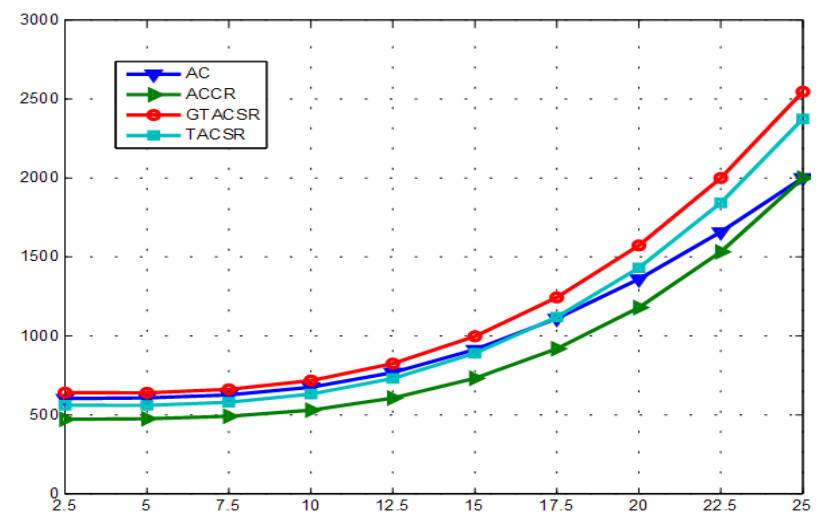

Fig. 6. Dependence of the tension of wires depending on wind speed.

From the above figures 5 and 6 and the calculations, we can conclude that the effect of wind pressure on the wires without ice is not a danger, therefore, even when the wind speed reaches $25 \mathrm{~m} / \mathrm{s}$, the tension on the wires does not exceed critical values, the overall dimensions of the lines are acceptable limits.

\section{Conclusion}

From the calculated data, it follows that the TACSR brand wire at maximum temperatures has the greatest value; therefore, the sag of such wires at maximum temperatures will be the smallest. Therefore, from the point of view of the influence of temperature on ensuring the high-voltage power transmission line reliability, the TACSR wire is optimal. The analysis of the results of the expected mechanical loads under the influence of natural factors showed that all the considered options for reconstruction of the $110 \mathrm{kV}$ high-voltage power lines satisfy the specified degrees of reliability.

\section{References}

[1] E.I. Gracheva, O.V. Naumov, Vliyanie rezhima raboty na veroyatnostnye kharakteristiki elektricheskikh ustroystv (Operating Mode Influence on Probability Characteristics of Electric Devices), Journal of engineering and applied sciences 11, 1, 2934-2938 (2016)

[2] E.I. Gracheva, O.V. Naumov, Estimation of Power Losses in Electric Devices of the Electrotechnical Complex, International Conference on Industrial Engineering, Applications and Manufacturing (ICIEAM) 6 (2019)

[3] D.S. Tolibjonovich, T.M. Islomovna, M.D. Saidulloevna, Modeling of starting transition processes of asynchronous motors with reduced voltage of the supply network, European Journal of Electrical Engineering 22, 1, 23-28. DOI: 10.18280/ejee.220103 (2020)

[4] M.I. Toshkhodzhaeva, Sravnitel'nyy analiz mekhanicheskikh svoystv traditsionnykh i vysokotemperaturnykh provodov vlep - $110 \mathrm{kV}$ (Comparative analysis of the mechanical properties of traditional and high-temperature vlep wires - $110 \mathrm{kV}$ ), Izvestiya Tul'skogo gosudarstvennogo universiteta, Tekhnicheskie nauki 3, 169-175 (2017)

[5] M.I. Toshkhodzhaeva, A.A. Khodzhiev, Osobennosti diagnostirovaniya vlep-110 kv v usloviyakh rezko kontinental'nogo klimata, (Features of diagnosing high-voltage power lines of $110 \mathrm{kV}$ in a sharply continental climate), Izvestiya Tul'skogo gosudarstvennogo universiteta, Tekhnicheskie nauki 2, 364-369 (2019)

[6] O.S. Rakhimov, A.A. Khodzhiev, M.I. Toshkhodzhaeva, Povyshenie nadezhnosti vlep$110 \mathrm{kv}$ na stadii proektirovaniya i ekspluatatsii (Improving the reliability of $110 \mathrm{kV}$ high-voltage power lines at the design and operation stages), Elektrooborudovanie: ekspluatatsiya i remont 3, 55-57 (2017)

[7] M. Amin, J. Stringer, The electric power grid: Today and tomorrow, MRS bulletin. 33, 04, 399407 (2008)

[8] W.C. Athas, et al., Low-power digital systems based on adiabatic-switching principles, IEEE Transactions on Very Large Scale Integration (VLSI) Systems 2, 4, 398-407 (1994)

[9] P.P. Barker, R.W. De Mello, Determining the impact of distributed generation on power systems. I. Radial distribution systems, Power Engineering Society Summer Meeting, IEEE 3, 1645-1656 (2000)

[10] L. Benini, A. Bogliolo, G. De Micheli, A survey of design techniques for system-level dynamic power management, IEEE transactions on very 
large scale integration (VLSI) systems 8, 3, 299316 (2000)

[11] P. Gregorio, M. Ahmadi, M. Buehler, Design, control, and energetics of an electrically actuated legged robot, IEEE Transactions on Systems, Man, and Cybernetics, Part B (Cybernetics) 27, 4 , 626-634 (1997)

[12] J. Henkel, A low power hardware/software partitioning approach for core-based embedded systems, Proceedings of the 36th annual ACM/IEEE Design Automation Conference, Berlin: ACM, 122-127 (1999)

[13] F. Kiessling, et al., Overhead power lines: planning, design, construction (Springer, 321, 2014)

[14] E. Lakervi, E.J. Holmes, Electricity distribution network design, IET, 21, 130-142 (1995)

[15] W. Li, et al., Reliability assessment of electric power systems using Monte Carlo methods (Springer Science \& Business Media, 540, 2013)

[16] R. Matsuoka, et al., Assessment of basic contamination withstand voltage characteristics of polymer insulators, IEEE transactions on power delivery 11, 4, 1895-1900 (1996)

[17] D.C. Montgomery, E.A. Peck, G.G. Vining, Introduction to linear regression analysis (California, John Wiley \& Sons, 821, 130, 2012)

[18] T.A. Reddy, Applied data analysis and modeling for energy engineers and scientists (Springer Science \& Business Media, 320, 2011)

[19] J. Schlichting, Molybdenum disilicide as a component of modern high-temperature composites, High Temperatures - High Pressures 10, 3, 241-269 (1978) 